\title{
Acetylcholinesterase and butyrylcholinesterase activity in the cerebrospinal fluid of patients with neurodegenerative diseases involving cholinergic
} systems

\author{
MERLE RUBERG,$^{*}$ ALBERT VILLAGEOIS, $\dagger$ ANNE-MARIE BONNET,* \\ BERNARD PILLON,* FRANÇOIS RIEGER, † YVES AGID* \\ From INSERM U.289 Laboratoire de Médecine Expérimentale* and Clinique de Neurologie et \\ Neuropsychologie Faculté de Médecine Pitié-Salpêtrière and INSERM U.153, $\uparrow$ Paris, France
}

SUMMARY Acetylcholinesterase (AChE) and butyrylcholinesterase (BChE) were assayed in the cerebrospinal fluid (CSF) of subjects with neurodegenerative diseases (dementing and nondementing, with and without known cholinergic lesions), to determine whether CSF AChE is a valid marker of central cholinergic activity. The relative proportions of the different forms of each enzyme and of AChE to BChE were similar in CSF and brain. AChE decreased in Huntington's chorea (degeneration of striatal cholinergic interneurons) but also in multiple sclerosis (not known to affect cholinergic systems). BChE paralleled $\mathrm{AChE}$, although the enzymes were dissociated in some patients. It is concluded that CSF AChE activity may globally reflect brain AChE, but 8 pathology-induced changes may not be directly reflected.

Interest in peripheral markers of central cholinergic activity has recently been revived by the discovery that cholinergic neurons in the basal forebrain (substantia innominata, septum, diagonal band of Broca) are affected in patients with Alzheimer-type dementia, ${ }^{1}$ as well as in patients with Parkinson's disease ${ }^{2}$ and progressive supranuclear palsy, ${ }^{3}$ diseases which are also associated with cognitive deficiencies. The degree of the neuronal disorder in both Alzheimer's and Parkinson's disease has been correlated with the severity of intellectual deterioration. ${ }^{24}$ Leaving aside the question of the therapeutic strategies this might suggest, hope was raised that a peripheral cholinergic marker reflecting central cholinergic activity would offer a clear criterion distinguishing degenerative dementia (Alzheimer's disease most importantly) from other tractable dementias and severe depression.

Results obtained in studies of acetylcholinesterase (AChE) in cerebrospinal fluid (CSF) of patients with Alzheimer's disease have been highly contradictory:

Address for reprint requests: Dr M Ruberg, Faculté de Médicine Pitié-Salpêtrière, 9 Blvd de l'Hôspital, 75013 Paris Cedex 13, France.

Received 13 May 1986 and in revised form 21 July 1986. Accepted 26 July 1986 no change in $\mathrm{AChE}{ }^{5-8}$ decreased $\mathrm{AChE},{ }^{9-12}$ increased $^{11}$ or decreased ${ }^{8} \mathrm{BChE}$ have been reported. In a recent study, ${ }^{8}$ neuropsychological test scores were found to correlate with $\mathrm{BChE}$ activity. Methodological differences might explain these discrepancies: assays of total cholinesterase activity or assays which distinguish $\mathrm{AChE}$ and $\mathrm{BChE}$, sampling procedure (lumbar or ventricular CSF), storage of samples, choice of control population. However, the hypothesis that CSF AChE reflects cholinergic innervation of the brain or central cholinergic activity (innervation and activity are not equivalent), is itself in need of validation. It is necessary to answer to three questions. Is $\mathrm{AChE}$, which is not found exclusively in cholinergic neurons, ${ }^{13}$ a valid marker of cholinergic innervation in the brain? Does $\mathrm{AChE}$ in cerebrospinal fluid reflect $\mathrm{AChE}$ activity in the brain? Can pathology-induced changes in brain AChE activity be detected in CSF?

A tentative answer to the first question was given in a previous study, ${ }^{14}$ where it was shown that $\mathrm{AChE}$ activity in the frontal cortex was significantly correlated with the activity of choline acetyltransferase (CAT), an enzyme found only in cholinergic neurons, and would seem, therefore, in spite of its lesser 
specificity, to be a valid marker of cholinergic innervation, at least in the cortex. To determine whether $\mathrm{AChE}$ activity in the cerebrospinal fluid may also be a valid marker of AChE activity in the brain, the different molecular forms of $\mathrm{AChE}$ and $\mathrm{BChE}$ were studied in the CSF of patients with a variety of degenerative diseases of the central nervous system, with and without dementia, with and without known cholinergic lesions.

\section{Material and methods}

\section{Subjects}

The subjects (tables 1 and 2) were all patients in the Clinique de Neurologie et Neuropsychologie of the Salpêtrière Hospi- tal in Paris, except for those with dystonia and the accompanying controls which were under treatment at the Dystonia Clinical Research Center, Columbia-Presbyterian Medical Center, New York. Diagnoses were made according to established criteria. Intellectual deterioration was assessed by standard neuropsychological tests of intellectual functions (memory, language, calculation), gestures, visuoconstructive activities, and frontal lobe function. An index of deterioration was calculated, as previously described. ${ }^{15}$

\section{Lumbar puncture}

Lumbar punctures were performed on patients after bed rest (12 hours in most cases). Serial aliquots of CSF were taken and immediately frozen. Assays were performed on aliquots representing the $10-12$ th $\mathrm{ml}$ of CSF, in order to minimise the effect of possible activity gradients.

Table 1 Dementia and/or cholinergic lesions in the patient

\begin{tabular}{|c|c|c|}
\hline Patient groups & Demented? & Cholinergic lesions? \\
\hline Controls-Paris $(\mathrm{Cl})$ & No & No \\
\hline Controls-New York (C2) & No & No \\
\hline Parkinson's disease (PD) (non-demented patients) & No & Innominato-cortical neurons: slight loss ${ }^{2}$ \\
\hline Parkinson's disease (demented patients) (PDD) & Yes & Innominato-cortical neurons: severe loss ${ }^{2}$ \\
\hline Alzheimer's disease (ALZ) & Yes & Innominato-cortical neurons: severe loss ${ }^{1}$ \\
\hline Progressive supranuclear palsy (PSP) & Yes & $\begin{array}{l}\text { Innominato-cortical neurons: slight loss; }{ }^{3} \text { striatal interneurons: } \\
\text { moderate loss }\end{array}$ \\
\hline Huntington's chorea (HC) & Yes & $\begin{array}{l}\text { Striatal interneurons: severe loss; innominato-cortical neurons: } \\
\text { intact }\end{array}$ \\
\hline Amyotrophic lateral sclerosis (ALS) & No & Peripheral motoneurons: severe loss ${ }^{21}$ \\
\hline Multiple sclerosis (MS) & No & No \\
\hline Torsion dystonia (childhood onset) (TDC) & No & No identified lesion; may respond to anticholinergic drugs ${ }^{22}$ \\
\hline Torsion dystonia (adult onset) (TDA) & No & No identified lesion; may respond to anticholinergic drugs ${ }^{22}$ \\
\hline
\end{tabular}

For origin of patients, see text ("Material and methods"). The diseases were chosen because they involve dementia and/or putative cholinergic lesions. The nature of the cholinergic lesion is indicated in the table. Superscript numbers are references concerning the diseases.

tble 2 Characteristics of the patients

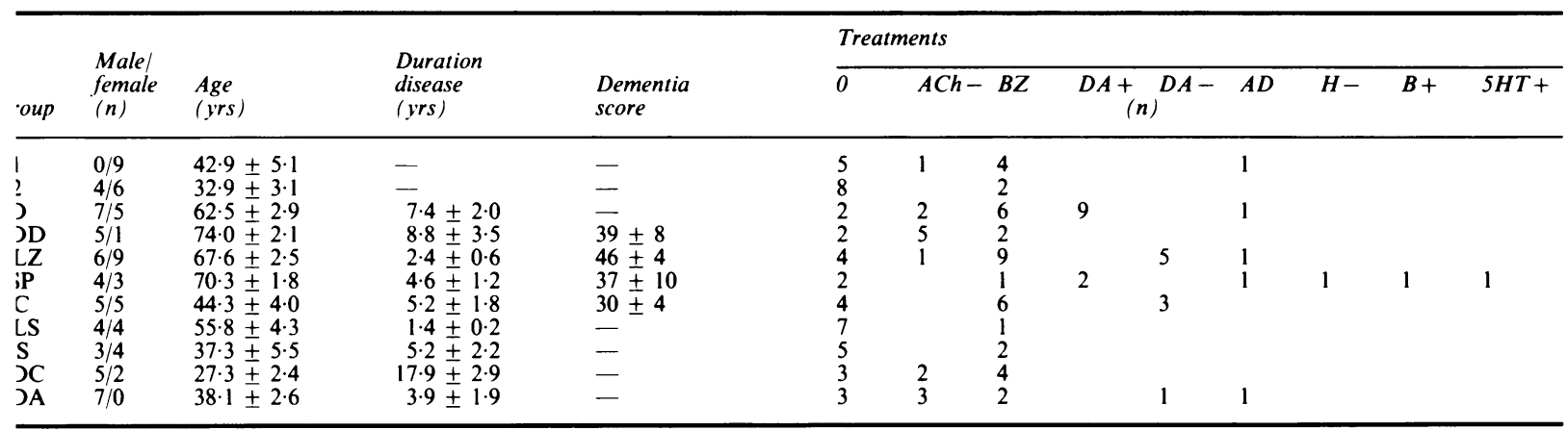

roup: The patient groups are identified as in Table 1.

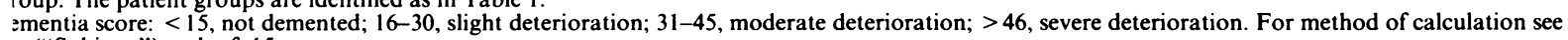
st ("Subjects") and ref. 15.

eatment: Drugs taken by patients (number in parentheses) at the time of lumbar puncture are indicated as follows: no treatment (0), anticholinergic ugs $(\mathrm{ACh}-)$, benzodiazepines $(\mathrm{BZ})$, dopamine agonists $(\mathrm{DA}+)$, neuroleptics $(\mathrm{DA}-)$, antidepressants $(\mathrm{AD})$, antihistamines $(\mathrm{H}-)$, beta-adrenergic onists $(\mathrm{B}+)$, serotonin agonists $(5 \mathrm{HT}+)$.

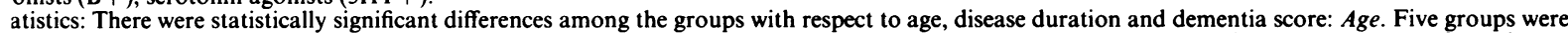

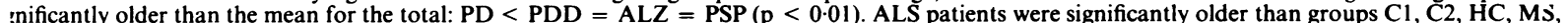

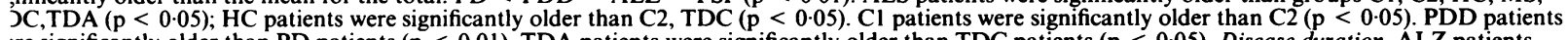

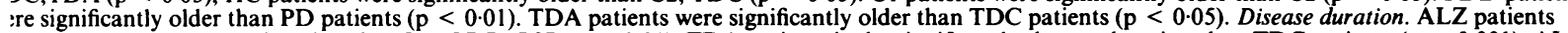

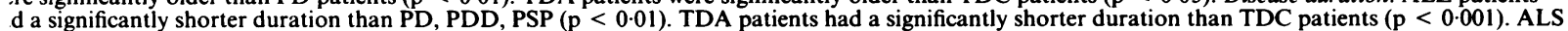
tients had a significantly shorter duration than TDC, PD, PDD (p < 0.05). Dementia score. HC patients had a significantly lower score etter performance) than ALZ patients ( $p<0.01$ ). 
Enzyme assays

As previously described, ${ }^{14}$ the molecular forms of $\mathrm{AChE}$ and BChE were separated by centrifugation of CSF $(100 \mu \mathrm{l})$ on sucrose gradients $(5-20 \%)$. Fractions $(300 \mu \mathrm{l})$ were collected and divided for assay of both enzymes according to the method of Ellman et al. ${ }^{16}$ Acetyl and butyrylthiocholine iodide were used as substrates. AChE was assayed in the presence of the $\mathrm{BChE}$ inhibitor isoOMPA (Sigma), and $\mathrm{BChE}$ in the presence of the AChE inhibitor BW284C51 (Burroughs Wellcome).

Protein concentrations were measured according to Lowry et al. ${ }^{17}$

\section{Results}

The sucrose gradient profiles of $\mathrm{AChE}$ and $\mathrm{BChE}$ in the CSF and frontal cortex of representative control subjects are shown in fig 1. The molecular forms of both enzymes were similar in CSF and brain homogenates with respect to the forms present, their sedimentation properties, the relative proportions of the different forms of each enzyme, and the relative proportions of $\mathrm{AChE}$ to $\mathrm{BChE}$.

In the subjects studied, total $\mathrm{AChE}$ and $10 \mathrm{~S} \mathrm{AChE}$, the principal form of the enzyme, were significantly correlated $(r=0.9444 ; p<0.001)$, as were total $\mathrm{BChE}$ and 10S BChE $(\mathrm{r}=0.9130 ; \mathrm{p}<0.001) .4 \mathrm{~S}$ and

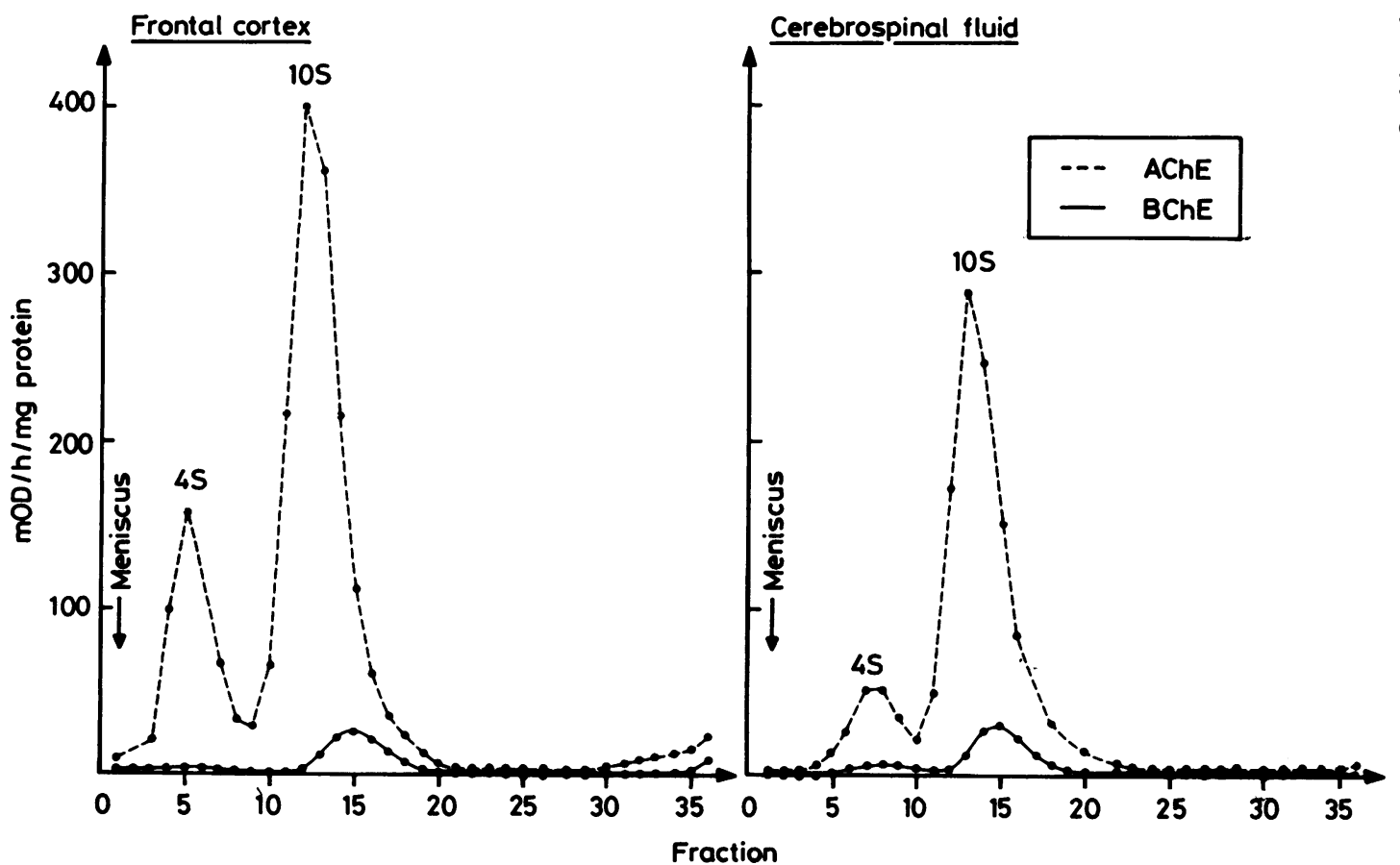

Fig 1 Molecular forms of $A C h E$ and $B C h E$ in frontal cortex and cerebrospinal fluid. The curves are examples of sucrose gradient profiles obtained with post-mortem brain tissue ${ }^{18}$ and cerebrospinal fluid from subjects with no known neurological disorders. Results are expressed as the change in optical density per hour at $412 \mathrm{~nm}$. Under our experimental conditions, a change in one optical density unit corresponds to the hydrolysis of $73.5 \mu \mathrm{mol}$ of acetyl-or butyrylthiocholine iodide.
10S AChE were also correlated $(r=0.5680 ; p<$ $0.001)$, as were $4 \mathrm{~S}$ and $10 \mathrm{~S} \mathrm{BChE}(\mathrm{r}=0.5524 ; \mathrm{p}<$ 0.001 ).

The concentrations of $10 \mathrm{~S} \mathrm{AChE}$ and $\mathrm{BChE}$ and protein in the CSF of the control and pathological subjects are shown in fig 2 . The levels of $10 \mathrm{~S} \mathrm{AChE}$ differed little among the various groups. They were significantly higher in demented Parkinsonian patients than in all the other groups except the controls, and significantly lower in patients with Huntington's chorea than all the other groups except for multiple sclerosis, progressive supranuclear palsy and non-demented Parkinsonians. 10S AChE in patients with multiple sclerosis was significantly lower than in controls.

Mean BChE activity paralleled that of AChE. 10S $\mathrm{AChE}$ and $10 \mathrm{~S} \mathrm{BChE}$ activity were significantly correlated when all subjects were grouped together $(r=$ $0.4823 ; p<0.001$ ). Significant correlations were also obtained within some of the groups, in spite of the small numbers of subjects: $\mathrm{C} 2(\mathrm{r}=0.7338 ; \mathrm{p}<0.02)$; $\operatorname{ALZ}(r=0.5875 ; p<0.05) ;$ TDA $(r=0.7877 ; p<$ 0.05). Sporadic cases of high BChE levels, dissociated from AChE concentrations, were occasionally observed. The mean $\mathrm{BChE} / \mathrm{AChE}$ ratio for all the patients was $0 \cdot 1524 \pm 0.008$. The mean of the child- 


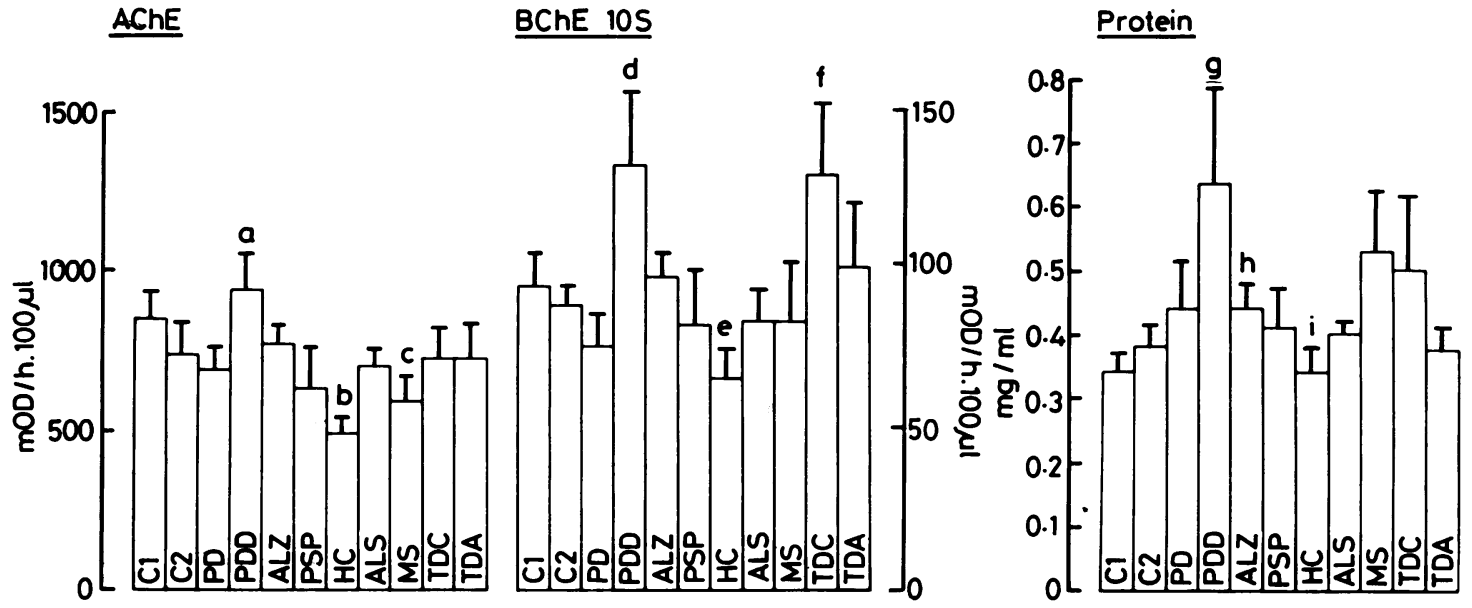

Fig 2 IOS AchE, IOS BchE and protein concentrations in CSF from patients with neurological diseases. The histograms represent the concentrations of $10 S A C h E, 10 S B C h E$ and protein in the CSF of each group of patients (mean $\pm S E M)$. Each bar represents a group of patients identified as in table 1. Statistically significant differences among the groups are indicated by the small letters: (a) AChE concentrations significantly higher $(p<0.05)$ in PDD patients than in PD, PSP, ALS, HC, MS, $T D A, T D C$ patients. (b) AChE concentrations significantly lower $(p<0.05)$ in $H C$ patients than in $C 1, C 2, A L Z, A L S$, $T D C$ and TDA patients. (c) AChE concentrations significantly lower $(p<0.05)$ in TDC patients than in CI patients.

(d) BChE concentrations significantly higher $(p<0.05)$ in PDD patients than in C1, PD,ALZ, ALS and HC patients.

(e) BChE concentrations significantly lower $(p<0.05)$ in HC patients than in C2,TDA,CI,PDD, ALZ and TDC patients.

(f) $B C h E$ concentrations significantly higher $(p<0.05)$ in TDC patients than in $C 2$ and PD patients. (g) Protein

concentrations significantly higher $(p<0.05)$ in $P D D$ patients than in $C 1$ and $C 2$ patients. (h) Protein concentrations significantly higher $(p<0.05)$ in ALZ patients than in Cl patients. (i) Protein concentrations significantly lower ( $p<0.05)$ in HC patients than in MS patients.

hood onset: dystonia group was significantly higher $(0 \cdot 1844 \pm 0 \cdot 0309)$ than that of the control groups and patients with Alzheimer's disease $(p<0.05)$.

The pattern of mean protein concentrations seemed to parallel that of the cholinergic enzymes in the groups of demented patients (Alzheimer's and Parkinson's diseases, progressive supranuclear palsy, Huntington's chorea), but were not correlated either within the groups or across the groups of demented patients. The mean elevated protein concentrations in certain groups of patients (Parkinson's disease, multiple sclerosis, torsion distonia) did not reflect the group as a whole but rather isolated cases, as indicated by the large standard errors of the means for these groups. One demented Parkinsonian patient and one childhood onset dystonia patient who had abnormally high CSF protein concentrations ( $>$ $1 \mathrm{~g} / \mathrm{ml}$ ), also had unusually elevated $10 \mathrm{~S} \mathrm{BChE}$ concentrations (BChE/AChE ratios $>0 \cdot 3$ ). There was, however, no consistent association between CSF protein and $\mathrm{BChE}$ concentrations.

There were no significant correlations with age, disease duration or drug treatment. Enzyme concentrations in demented patients were not correlated with the global deterioration score or performance on individual neuropsychological tests.

\section{Discussion}

It had previously been shown that $\mathrm{AChE}$ activity in frontal cortex is correlated with CAT activity, a specific marker of cholinergic innervation, indicating that it may also be a valid marker of cholinergic innervation in the brain, at least in the frontal cortex. ${ }^{14}$ When the sucrose gradient profiles of AChE and $\mathrm{BChE}$ in CSF from normal subjects were compared with those obtained with brain homogenates, it was observed that the same forms of the enzymes were present, in the same proportions. Concentrations of the enzymes in the CSF may, therefore, reflect the concentrations of the enzymes in the brain, globally. This observation does not, however, support the hypothesis that a specific form of $\mathrm{AChE}$, the $10 \mathrm{~S}$ enzyme ${ }^{13}$ is actively released from cholinergic neurons. 10S AChE is not preferentially found in the CSF, and cannot, therefore, serve as a marker of cholinergic activity in the brain as a whole or in specific. neuronal systems. This was confirmed when the molecular forms of $\mathrm{AChE}$ and $\mathrm{BChE}$ were analysed in the CSF of patients with putative cholinergic lesions.

The most striking illustration is the results obtained with Parkinsonian patients. It was previously shown 
that cortical AChE, like cortical CAT activity, decreased in Parkinsonian patients as a function of their degree of intellectual deterioration; a significant difference was observed between non-demented Parkinsonians and controls and between demented and non-demented Parkinsonians. ${ }^{14}$ In the CSF, however, AChE levels in non-demented Parkinsonian patients were similar to those of controls, whereas in demented Parkinsonian patients, they were significantly higher than in non-demented patients.:

The inexplicable decrease in CSF AChE in patients with multiple sclerosis is also instructive: in this demyelinating disease, there are no known specific cholinergic lesions, yet mean CSF AChE activity was lower than in all the other groups except the patients with Huntington's chorea, whereas AChE concentrations were similar to controls in diseases with known cholinergic lesions. CSF AChE levels were significantly lower in patients with cholinergic lesions of the striatum (Huntington's chorea) whereas other cholinergic lesions such as those of the innominatocortical system (Parkinson's disease, Alzheimer's disease, progressive supranuclear palsy) or anterior horn cells of the spinal cord (amyotrophic lateral sclerosis) were not detectable. The severity of the lesion in patients with Huntington's disease may explain the difference, but this remains to be demonstrated. The proximity of the striatum to brain ventricles may also render the cholinergic lesion in patients with Huntington's disease more "visible" in the CSF than lesions in regions with less direct access to the fluid. The putative "visibility" of the striatal lesion in patients with Huntington's disease and the "invisibility" of cholinergic cell loss in the spinal cord of patients with amyotrophic lateral sclerosis is evidence that the results obtained were not biased by sampling lumbar CSF, under the conditions of these experiments.

If CSF AChE levels do not reflect known cholinergic lesions, they reflect even less the functional consequences of these lesions, in particular dementia. In the first place, the cognitive deficiencies in patients with Parkinson's disease, Alzheimer's disease and supranuclear palsy are not due uniquely to lesions of the innominato-cortical system, ${ }^{18}$ and patients may become demented without this cholinergic lesion (Huntington's chorea).

It has been suggested, on the basis of studies showing increases in BChE activity in brain ${ }^{19}$ or $\mathrm{CSF}^{11}$ of patients with Alzheimer's disease that the ratio of the two enzymes would better distinguish these subjects than the individual enzymes. The present results do not confirm this hypothesis. BChE activity in the CSF was found to be correlated with AChE activity, and the ratio of the enzymes was similar in all the groups with the exception of childhood onset dystonia.
BChE levels are slightly elevated in some of these patients, for reasons which are unknown. Elevated levels of the enzyme were also observed in a few isolated patients in other groups as well. The reason for this is unknown, as is the function of this enzyme. It is thought to be located for the most part in glial cells, ${ }^{13}$ but the parallel between AChE and BChE in the CSF, and the similar effects of pathological conditions on the two enzymes suggest that the synthesis and regulation of the enzymes may be closely related, but not necessarily so, since dissociation of the enzymes was observed in some cases. It is possible that only BChE released in parallel with AChE from central neurons is found in the CSF, whereas glial enzyme does not reach this compartment. However, the observation that the ratio between $\mathrm{AChE}$ and $\mathrm{BChE}$ is similar in brain tissue and CSF would not be consistent with this hypothesis.

In conclusion, although AChE may be considered a valid marker of cholinergic innervation in the brain, and AChE activity in the CSF may reflect AChE activity in the brain, pathologically induced changes in brain AChE activity are not directly reflected in the concentrations of AChE in the CSF, and will, therefore, not provide the diagnostic marker anticipated. Results obtained in previous studies of AChE in the CSF of patients with Alzheimer's disease are consistent with this conclusion.

The authors thank Dr François Lhermitte (Clinique de Neurologie et Neuropsychologie of the Salpêtrière Hospital) and Dr Stanley Fahn (College of Physicians and Surgeons, Columbia University) for making this study possible. This study was financed in part by the DRET (contract number: 84054).

\section{References}

1 Rossor MN. Dementia. Lancet 1982;ii:1200-4.

2 Dubois B, Ruberg M, Javoy-Agid F, Ploska A, Agid Y. A subcortico-cortical cholinergic system is affected in Parkinson's disease. Brain Res 1983;288:213-8.

3 Ruberg M, Javoy-Agid F, Hirsch E, et al. Dopaminergic and cholinergic lesions in progressive supranuclear palsy. Ann Neurol 1985; 18:523-9.

4 Perry EK, Curtis M, Dick D, et al. Cholinergic correlates of cognitive impairment in Parkinson's disease: comparisons with Alzheimer's disease. $J$ Neurol Neurosurg Psychiatry 1985;48:413-21.

5 Davies P. Neurotransmitter-related enzymes in senile dementia of the Alzheimer type. Brain Res 1979; 171:319-27.

6 Deutsch SI, Mohs RC, Rothpearl TB, Horvath YB, Davis K. CSF acetylcholinesterase activity in neuropsychiatric disorders. Biol Psychiatry 1983; 18: 1363-73.

7 Lal S, Wood PL; Kiely ME, et al. CSF acetylcholinesterase in dementia and in sequential samples 
of lumbar CSF. Neurobiol Aging 1984;5:269-74.

8 Huff FJ, Maire JC, Growdon JH, Corkin S, Wurtman $\mathrm{RJ}$. Cholinesterases in cerebrospinal fluid: correlations with clinical measures in Alzheimer's disease. J Neurol Sci 1986;72:121-9.

9 Soininen HS, Jolkkonen JT, Reinikainen KJ, Halonen TO, Riekkinen PJ. Reduced cholinesterase activity and somatostatin-like immunoreactivity in the cerebrospinal fluid of patients with dementia of Alzheimer type. J Neurol Sci 1984;63:167-72.

10 Appleyard ME, Smith AD, Wilcock GK, Esiri MM. Decreased CSF acetylcholinesterase activity in Alzheimer's disease. Lancet 1983;ii:452.

11 Arendt T, Bigl V, Walther F, Sonntag M. Decreased ratio of CSF acetylcholinesterase to butyrylcholinesterase activity in Alzheimer's disease. Lancet 1984;i:173.

12 Tune LS, Gucker S, Folstein M, Oshida L, Coyle JT. Cerebrospinal fluid acetylcholinesterase in dementia of the Alzheimer type. Ann Neurol 1985;17:46-8.

13 Massoulie J, Bon S. The molecular forms of cholinesterase and acetylcholinesterase in vertebrates. Ann Rev Neurosci 1982;5:57-106.

14 Ruberg M, Rieger F, Villageois A, Bonnet AM, Agid Y. Acetylcholinesterase and butyrylcholinesterase in frontal cortex and cerebrospinal fluid of demented and non-demented patients with Parkinson's disease. Brain Res 1986;362:83-91.

15 Pillon B, Agid Y, Dubois B, Lhermitte F. Heterogeneity of intellectual impairment in progressive supranuclear palsy, Parkinson's and Alzheimer's disease. Neurology 1986;36:1179-85.

16 Ellman GL, Courtney DD, Andres V, Featherstone RM. $A$ new and rapid colorimetric determination of acetylcholinesterase activity. Biochem Pharmacol 1961;1:88-95.

17 Lowry OH, Rosebrough NJ, Farr AL, Randall RM. Protein measurement with the Folin phenol reagent. $J$ Biol Chem 1951;193:265-75.

18 Ruberg M, Agid Y. Dementia in Parkinson's disease. In: Iversen L, Iversen S, Snyder S, eds. Handbook of Psychopharmacology, vol. 20: Psychopharmacology of the aging nervous system. New York: Plenum Publishing Corporation (in press).

19 Perry EK, Tomlinson BE, Blessed G, Bergmann K, Gibson PH, Perry RH. Correlation of cholinergic abnormalities with senile plaques and mental test scores in senile dementia. Br Med J 1978;ii:1457-9.

20 Bradley WC, Munsat TL, Pelnam RW, et al. The etiology of ALS. In: Kidman AD, Tomkins, eds. Muscle Nerve and Brain Degeneration. Amsterdam: Excerpta Medica, 1979:67-84.

21 Klawans HL, Rubovits R. Central cholinergicanticholinergic antagonism in Huntington's chorea. Neurology 1972;22:107-16.

22 Fahn S. High dosage anticholinergic therapy in dystonia. Neurology 1983;33:1255-61. 